\title{
Radical Vaginal Trachelectomy
}

\author{
Tsuyoshi Saito, MD, $\mathrm{PhD}^{1}$ Motoki Matsuura, $\mathrm{MD}, \mathrm{PhD}^{1}$ Masato Tamate, $\mathrm{MD}, \mathrm{PhD}^{1}$ \\ Masahiro Iwasaki, MD, $\mathrm{PhD}^{1}$ Tasuku Mariya, MD, $\mathrm{PhD}^{1}$
}

${ }^{1}$ Department of Obstetrics and Gynecology, Sapporo Medical
University, Sapporo, Japan

Surg J (NY) 2021;7(suppl S2):S103-S107.
Address for correspondence Tsuyoshi Saito, MD, PhD, Department of Obstetrics and Gynecology, Sapporo Medical University, Chuo-ku S-1 W-16, Sapporo 060-8543, Japan (e-mail: desmoplakin@gmail.com).

\begin{abstract}
Keywords

- cervical cancer

- trachelectomy

- laparoscopically assisted radical vaginal hysterectomy

- fertility

- laparoscopy

- minimal invasiveness

Recently, radical vaginal hysterectomy (RVH) has developed into laparoscopically assisted radical vaginal hysterectomy (LARVH), which is associated with the laparoscopical procedure, and it is applied as radical vaginal trachelectomy and semi-radical vaginal hysterectomy. LARVH is indicated for patients with stage IB1 and IIA1 cervical carcinoma, especially those with a tumor size of less than $2 \mathrm{~cm}$, because the cardinal ligaments cannot be resected widely. Although RVH that is associated with laparoscopic pelvic lymphadenectomy is the most used surgical procedure, radical trachelectomy may be performed either abdominally or vaginally (laparoscopic or robotic). One report found that the pregnancy rate was higher in patients who underwent minimally invasive or radical vaginal trachelectomy than in those who underwent radical abdominal trachelectomy.
\end{abstract}

\section{History of Radical Vaginal Hysterectomy and Radical Vaginal Trachelectomy}

In 1908, Schauta first described radical vaginal hysterectomy $(\mathrm{RVH}){ }^{1}$ After making several improvements, Amreich performed a radical resection of the parametrial ligament, according to a new anatomical knowledge. ${ }^{2}$ With a wide surgical field, these RVH procedures incise the vagina, perineum, and levator ani muscle. For cervical carcinoma, RVH was performed more often than abdominal radical hysterectomy $(\mathrm{RH})$ because of its lower surgical invasiveness. However, RVH was selected only for early carcinoma cases because lymphadenectomy was impossible to perform. Later, Navratil ${ }^{3}$ described RVH with extraperitoneal lymphadenectomy in which both abdominal sides were incised. In Japan, Akashi ${ }^{4}$ demonstrated a modified Mitra method as an RVH procedure ${ }^{5}$ in which extraperitoneal lymphadenectomy and parametrial vessel interruption were performed after a vaginal procedure. Some European countries, such as Germany and Austria, adopt the RVH; however, its use has been limited. To increase the application of RVH, Dargent ${ }^{6}$ proposed that the bilateral abdominal incision method should be replaced with laparoscopy, which has been part of

published online December 1, 2021
DOI https://doi.org/ $10.1055 / \mathrm{s}-0041-1739120$. ISSN 2378-5128. the RH procedure since Meigs' study for a systematic pelvic dissection. Recently, RVH has evolved into laparoscopically assisted RVH, which is associated with the laparoscopic procedure $^{7}$ and is applied as radical vaginal trachelectomy (RVT) ${ }^{8}$ and semiradical vaginal hysterectomy. ${ }^{9}$

\section{Principle and Indication}

Trachelectomy is the removal of the cervix, upper vagina, and parametrium (tissue surrounding the cervix). Pelvic lymph nodes may also be removed. Some cases of early-stage cervical cancer in women who wish to keep their fertility and ability to be pregnant can be treated with RVT. In particular, it is indicated for patients with stage IB1 and IIA1 cervical carcinoma, especially those with a tumor size $<2 \mathrm{~cm}$, because the cardinal ligaments can be resected widely.

\section{Preoperative Evaluation}

Cervical carcinoma is diagnosed according to the histologic examination of tissues obtained after conization or from a biopsy under colposcopy. For cervical carcinomas, tumor

(C) 2021. The Author(s).

This is an open access article published by Thieme under the terms of the Creative Commons Attribution License, permitting unrestricted use, distribution, and reproduction so long as the original work is properly cited. (https://creativecommons.org/licenses/by/4.0/)

Thieme Medical Publishers, Inc., 333 Seventh Avenue, 18th Floor, New York, NY 10001, USA 
progression is routinely evaluated by digital rectal examination, computed tomography (CT), and magnetic resonance imaging (MRI). Abdominal hysterectomy is recommended for patients with parametrium-invading tumor, tumor size $>2 \mathrm{~cm}$, and/or narrow vagina. The surgeon must perform colposcopy precisely to determine the correct incision areas. In colposcopy, the vaginal orifice is stretched, and Schuchardt episiotomy is performed for an especially narrow vagina.

\section{Surgical Steps}

1. Pelvic lymphadenectomy. $\downarrow$

2. Vaginal retractors and decision of the incision site. $\downarrow$

3. Incision of the vaginal wall. $\downarrow$

4. Opening the vesicovaginal space. $\downarrow$

5. Opening the paravesical space. $\downarrow$

6. Division of the inner vesicouterine ligament. $\downarrow$

7. Division of the cardinal ligament. $\downarrow$

8. Excision of the cervix and reconstruction of a neocervix.

\section{Technique}

\section{Pelvic Lymphadenectomy}

Originally done extraperitoneally, pelvic lymphadenectomy has been recently performed laparoscopically using the classical peritoneal route. The round ligaments and ovaryspecific ligaments are sealed and incised using energy modalities. After expanding the retroperitoneum, the surgeon dissects the pelvic lymph nodes. Unlike the medial aspect of the iliac vessels, the lateral aspect is difficult to clean; however, it can be achieved laparoscopically as effectively as during laparotomy.

\section{Vaginal Retractors and Decision of the Incision Site}

In this procedure, the labia are sutured first to the medial aspect of the thigh. Vaginal retractors are positioned at four points in the vagina. Relatively short vaginal retractors $(2.0 \times 6.0 \mathrm{~cm})$ are set anteriorly and posteriorly, whereas midsized vaginal retractors $(2.5 \times 8.5 \mathrm{~cm})$ are set laterally. After placing the retractors, the surgeon determines the site of the incision into the vaginal wall for lesion removal. The incision line slightly varies between individual cases. Preoperative colposcopy and the Schiller iodine test are employed to determine the incision areas in the vaginal wall, and the incision line should be approximately $2 \mathrm{~cm}$ away from the borderline of the abnormal epithelium. In almost all cases in

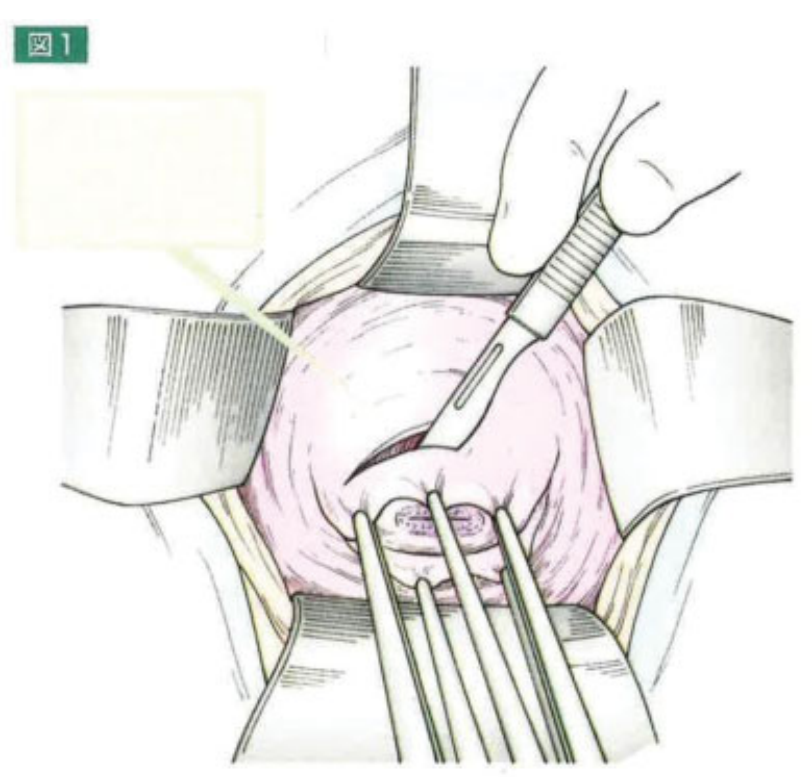

Fig. 1 Incision of the vaginal wall. Comment: The surgeon clamps and lifts the vaginal wall by using short Kocher hemostatic forceps at 6 to 8 points in $5 \mathrm{~mm}$ front of the resection site. After epinephrine injection, a circular incision is made to a depth of approximately $5 \mathrm{~mm}$.

which the epithelium is located at the cervix without lateral invasion to the vaginal cuff, the vaginal resection from the portio is approximately $1.0 \mathrm{~cm}$ long. Vaginal resection is performed intraoperatively for traction to prevent vaginal vault recurrence.

\section{Incision of the Vaginal Wall}

After the resection site is determined, the vaginal wall is clamped and lifted using short Kocher hemostatic forceps at 6 to 8 points, conforming to a line circumscribing the cervix. The incision site and the planes between the bladder and vagina are injected with epinephrine $(0.1 \%$ diluted in $100 \mathrm{~mL}$ of saline solution). The forceps are brought forward simultaneously, and a circular incision is made to a depth of approximately $5 \mathrm{~mm}$ (-Fig. $\mathbf{1}$ ).

\section{Opening the Vesicovaginal Space}

Using the Kocher hemostatic forceps, the surgeon clamps the upper edge of the vaginal wall at two positions and then retracted upward. Then, the surgeon divides the fascia vaginalis and opens the vesicovaginal space by using curved operating scissors (-Fig. 2). While covering the uterus, the surgeon separates the bladder by inserting the forefinger into the space between the bladder and peritoneum. Similarly, the posterior fascia is divided using such a pair of scissors. The surgeon places the traction sutures (manchette) near the fascial incision, covering the fascia in the front and behind, and the lateral portions of the cuff as the integument. The sutures are left long, knotted together, and used for uterine retraction (-Fig. 3 ).

\section{Opening the Paravesical Space}

The traction sutures are retracted laterally to the lower right to expose the left side. Furthermore, the vaginal wall is clamped with Kocher forceps at 2 o'clock position and 


\section{图2}

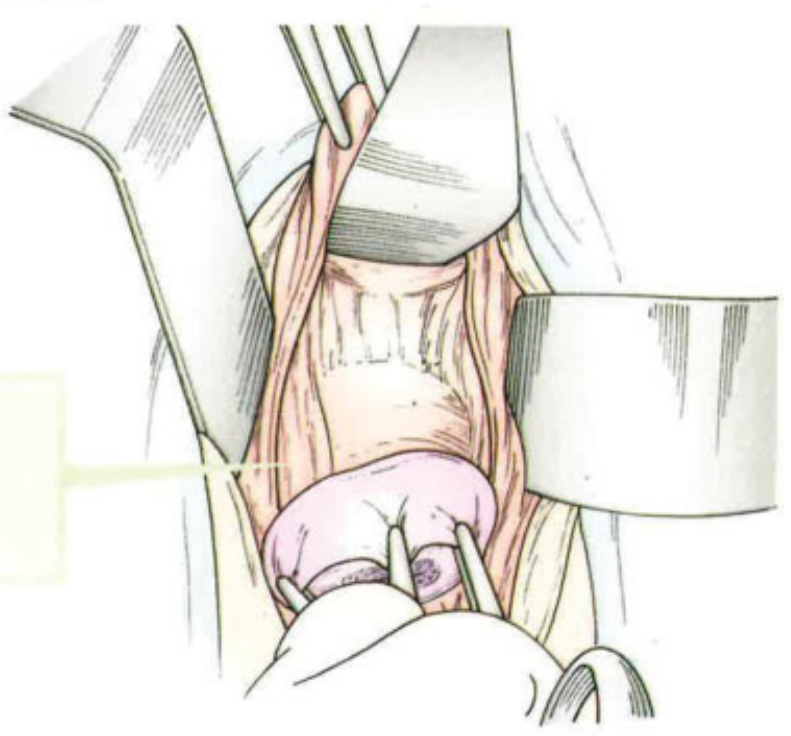

Fig. 2 Opening the vesicovaginal space. Comment: Using the Kocher hemostatic forceps, the surgeon clamps the upper edge of the vaginal wall at two positions, followed by upward retraction. Then, using curved operating scissors, the surgeon divides the fascia vaginalis and opens the vesicovaginal space.

retracted to the upper left. The surgeon then divides the lateral side of the vesicouterine ligament from the vaginal wall by using a pair of curved scissors (-Fig. 4). The paravesical space is then opened by inserting a forefinger or scissors, penetrating the space horizontally and to a point at the upper left of the incision area.

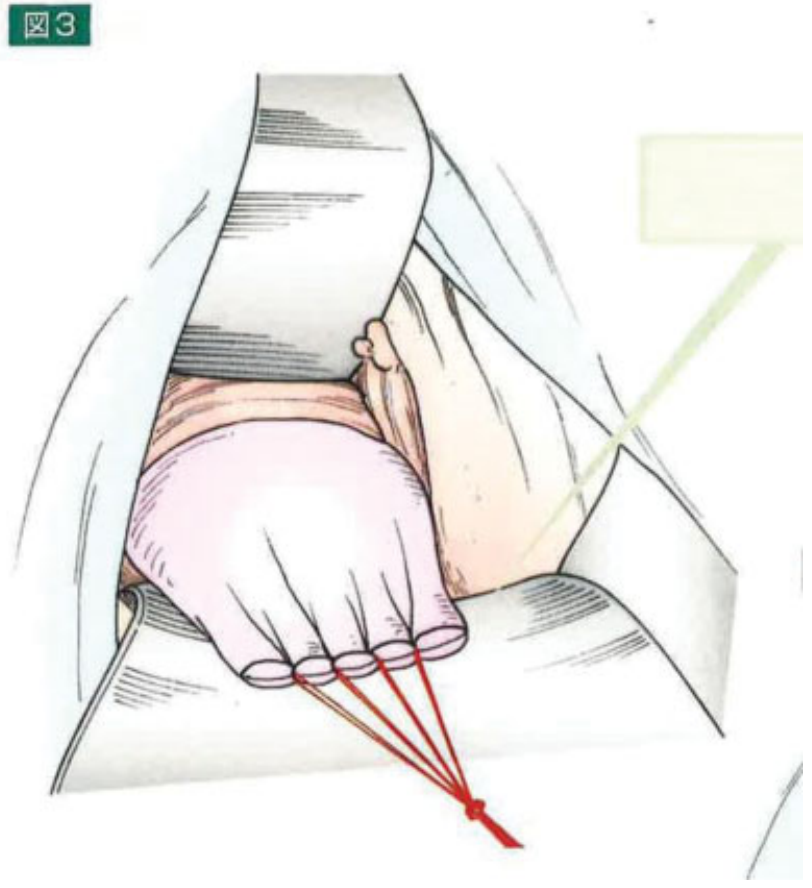

Fig. 3 Contraction of Manchette. Comment: To separate the bladder, the surgeon's forefinger is inserted into the space between the bladder and peritoneum, covering the uterus.

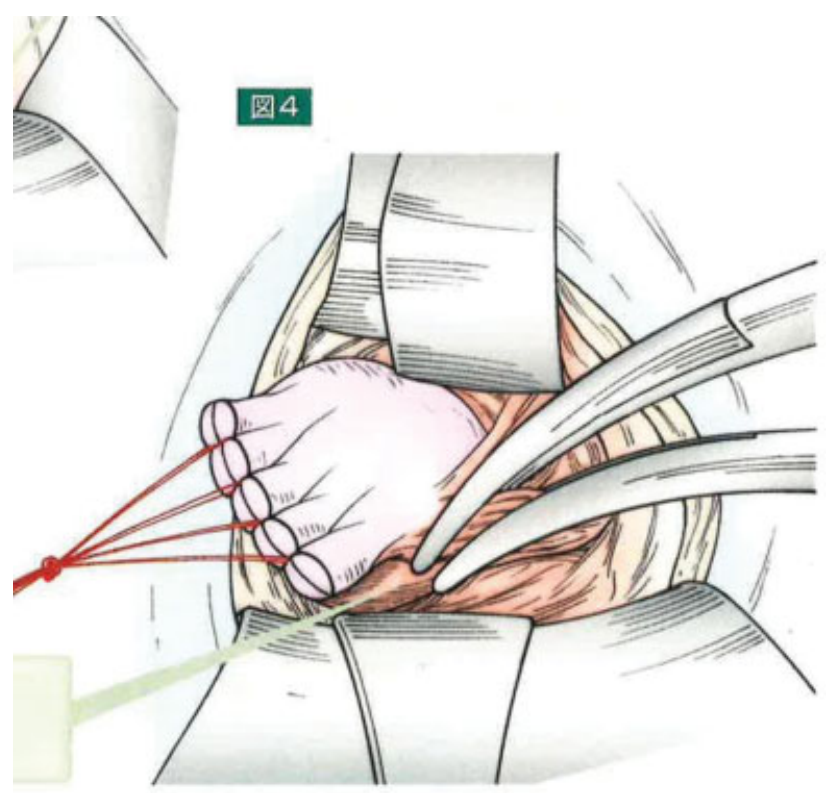

Fig. 4 Division of the vesicouterine ligament. Comment: The lateral side of the vesicouterine ligament from the vaginal wall is divided using a pair of curved scissors.

For penetrating the paravesical and retrovaginal spaces, the paracolpos is hooked with the forefinger or curved forceps. Then, a midsized vaginal retractor $(2.5 \times 8.5 \mathrm{~cm})$ is inserted into the paravesical space. The paracolpos is subsequently clamped, divided, and transfixion-sutured with a 20 polyglycolic acid suture.

\section{Division of the Inner Vesicouterine Ligament}

The uterus is firmly extended to the lower right by retracting the bladder and stretching the vesicouterine ligament longitudinally. To confirm its position, the ureter must be felt and touched

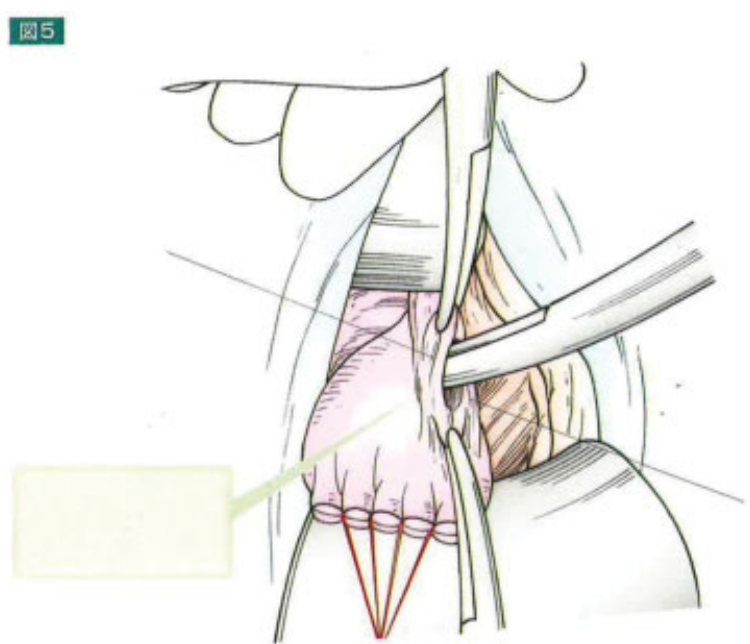

Fig. 5 Division of the inner vesicouterine ligament and creation of the ureteric tunnel. Comment: The surgeon clamps the outer top of the external vesicouterine ligament in two places and divides it using a pair of curved scissors, which are then passed into the ureteric tunnel from the divided area by gentle dissection. 


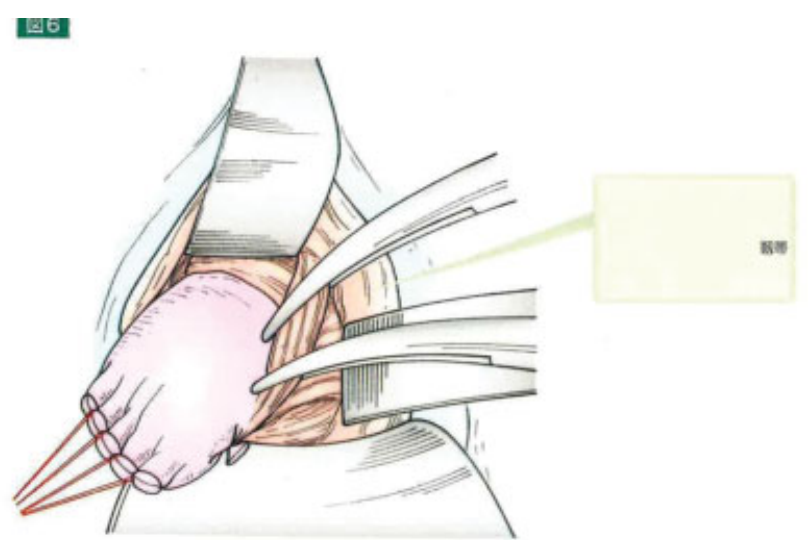

Fig. 6 Division of the outer vesicouterine ligaments. Comment: The surgeon preserves the outer vesicouterine ligaments, which contain the bladder branch of the pelvic splanchnic nerve, to exclude them at the dorsal side and partially divide them using curved operating scissors.

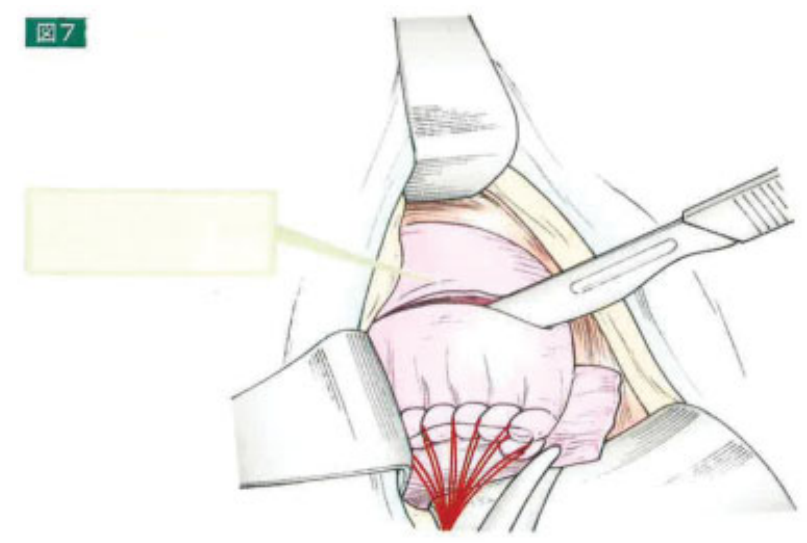

Fig. 7 Division of the uterus. Comment: The uterus is transected 5 to $10 \mathrm{~mm}$ underneath the isthmus.

between the forefinger and middle finger. The outer top of the external vesicouterine ligament is clamped in two places and then divided using a pair of curved scissors ( - Fig. 5 ). Thereafter, the clamps are replaced with a 2-0 polyglycolic acid transfixion suture. From the divided area, the curved scissors are passed into the ureteric tunnel through gentle dissection. Using the same maneuver, the surgeon divides the inner vesicouterine ligament into two or three separate stages. After the inner vesicouterine ligament is separated and ligated, the site where the uterine artery crosses the ureter is seen clearly. The uterine artery, which has already been divided laparoscopically, is pulled out. The outer vesicouterine ligaments, which contain the bladder branch of the pelvic splanchnic nerve, are preserved to exclude them at the dorsal side, and they are partially divided using the curved operating scissors (-Fig. 6). Thus, the procedure corresponds to levels II and III of the Piver classification. ${ }^{10}$

\section{Division of the Cardinal Ligament}

The surgeon placed a curved clamp (or finely serrated multipurpose forceps) approximately $2 \mathrm{~cm}$ from the cervical edge, and the cardinal ligament is divided and resected near

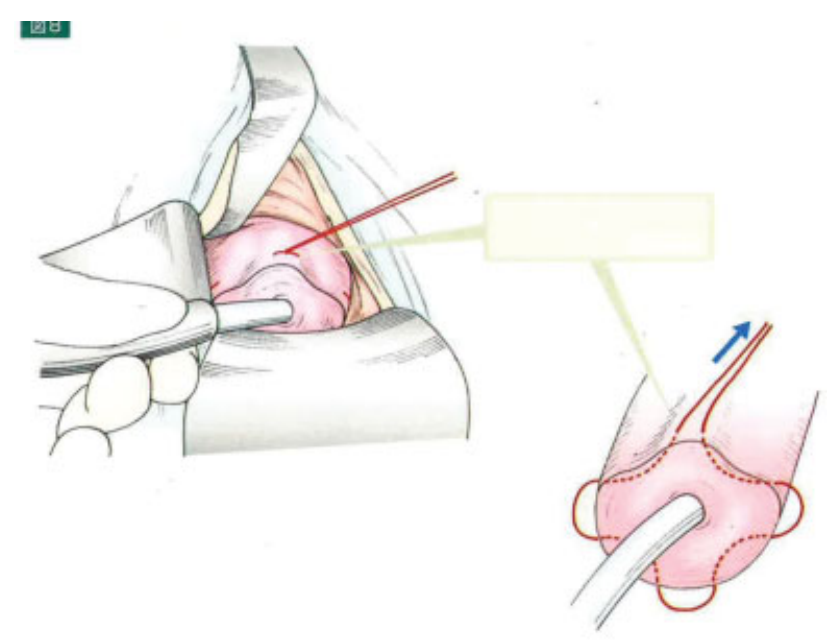

Fig. 8 McDonald Cerclage. Comment: The surgeon established a cerclage around the isthmus.

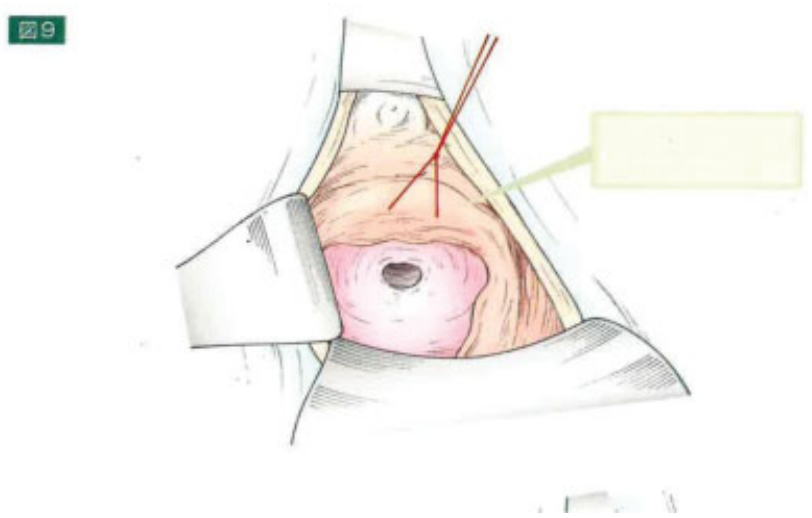

Fig. 9 Reanastomosis of the vagina to the isthmus. Comment: McDonald cerclage is placed to create an artificial opening into the uterus.

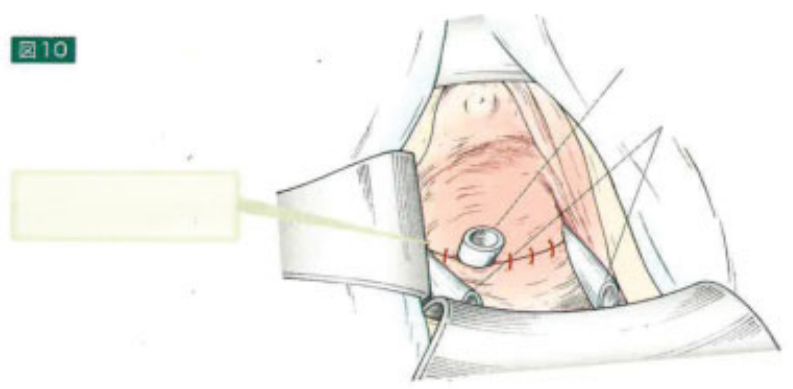

Fig. 10 Catheter insertion. Comment: To keep the space open, the surgeon may insert a catheter.

where the uterine artery and ureter cross. The same procedure is used for the right side. However, the surgeon can only resect the cardinal ligament after the anterior part of the peritoneum is opened.

\section{Excision of the Cervix and Reconstruction of a Neocervix}

The procedure ends by dividing the uterus that is transected 5 to $10 \mathrm{~mm}$ underneath the isthmus (-Fig. 7). For the 
neocervical reconstruction, the pouch of Douglas is closed, putting a cerclage around the isthmus (McDonald cerclage, - Fig. 8), and the vagina is reanastomosed to the isthmus (-Fig. 9). McDonald cerclage is placed to create an artificial opening into the uterus, considering that the cervical os is already absent. Hence, menstrual blood can still pass. A catheter may be inserted to keep the space open (-Fig. 10).

\section{Conflict of Interest}

None declared.

\section{References}

1 Schauta F. Die erweiterte vaginal total Exsirpation des Uterus bei Collumcarcinoma. Austria: Safer Wien-Lepzig1908

2 Amreich I. Zur Anatomie und Technik der erweiterten vaginalen Carcinomoreration. Arch Gynakol 1924;122:497-553

3 Navratil E. Radical vaginal panhysterectomy and pelvic lymphadenectomy. incongress on Obstetrics and Gynecology. St Louis: CV Mosby; 1951
4 Akashi K. [The extraperitoneal vaginal ultra radical surgery of cancer of the collum]. Arch Gynakol 1967;204(02):25-26

5 Mitra S. Extraperitoneal lymphadenectomy and radical vaginal hysterectomy for cancer of the cervix (Mitra technique). Am J Obstet Gynecol 1959;78(01):191-196

6 Dargent D, Mathevet P. [Radical laparoscopic vaginal hysterectomy]. J Gynecol Obstet Biol Reprod (Paris) 1992;21(06): 709-710

7 Pergialiotis V, Rodolakis A, Christakis D, Thomakos N, Vlachos G, Antsaklis A. Laparoscopically assisted vaginal radical hysterectomy: systematic review of the literature. J Minim Invasive Gynecol 2013;20(06):745-753

8 Ishioka S, Endo T, Hayashi T, Baba T, Umemura K, Saito T. Pregnancy-related complications after vaginal radical trachelectomy for early-stage invasive uterine cervical cancer. Int J Clin Oncol 2007;12(05):350-355

9 Kudo R, Ito E, Kusanagi T, Hashimoto M. Vaginal semiradical hysterectomy: a new operative procedure for microinvasive carcinoma of the cervix. Obstet Gynecol 1984;64(06):810-815

10 Piver MS, Rutledge F, Smith JP. Five classes of extended hysterectomy for women with cervical cancer. Obstet Gynecol 1974;44 (02):265-272 